\title{
The Implementation of the Low Voltage Ride-Through Curve on the Protection System of a Wind Power Plant
}

\author{
R.P.S. Leão ${ }^{1}$, J.B. Almada ${ }^{1}$, P.A. Souza ${ }^{2}$, R.J. Cardoso ${ }^{1}$, \\ R.F. Sampaio ${ }^{1}$, F.K.A. Lima ${ }^{1}$, J.G. Silveira ${ }^{2}$ and L.E.P. Formiga ${ }^{2}$ \\ ${ }^{1}$ Department of Electrical Engineering \\ Federal University of Ceara \\ Campus do Pici - Caixa Postal 6001, CEP: 60455-760, Fortaleza - CE (Brasil) \\ Phone: +005585 3366.9580, e-mail: rleao@dee.ufc.br, janainaalma@gmail.com,r.cardoso16@gmail.com, \\ rfurtado@dee.ufc.br,klima@dee.ufc.br \\ ${ }^{2}$ Companhia Energética do Ceará - Coelce \\ Maintenance, Protection and Automation \\ Rua Pe. Valdevino, 150, CEP: 60135-040, Fortaleza - CE (Brasil) \\ Phone: +0055 85 3216.4125, e-mail: patrick@coelce.com.br, giordane@coelce.com.br, formiga@coelce.com.br
}

\begin{abstract}
This paper presents the implementation of the low voltage ride-through (LVRT) curve in two commercial numerical relays, assessing the features and limitations of each protection device. The LVRT curve is defined in grid codes of several countries, especially those who already have or are planning a high share of wind power in their electric power systems. The functionality of the wind turbine grid protection system is tested in a power system using the PSCAD/EMTDC simulation tool. The fault ride through capability curve applied in the test system is as defined in the Brazilian grid code and the protection system responses evaluated at the point of common coupling of the wind power plant when the power network is under symmetrical and unsymmetrical faults. The biggest challenge to adhere the system operator requirements is to ensure the highest conformity to the defined LVRT curve, because most relays only gives you the option of tuning in discrete time intervals.
\end{abstract}

\section{Key words}

Low voltage ride-through, Numerical relays, Wind power plant, Doubly-fed induction generator.

\section{Introduction}

As the wind power plants increase in size and command a larger share of supply portfolio, they are required to stay operational and not disconnect from the grid supporting the grid with reactive power during and after voltage sags [1]. Such requirements are known as Fault Ride-Through (FRT) or Low Voltage Ride-Through (LVRT) capability. Low voltage ride-through is a condition required to the wind generators when the voltage in the grid is temporarily reduced due to a fault or large load change in the grid. The voltage may be reduced in one, two or all the three phases of the ac grid. The required low voltage ride-through (LVRT) behavior is defined in grid codes issued by the grid operators in order to maintain high availability and system stability, reducing the risk of voltage collapse $[2,3,4]$. LVRT enhances this feature by keeping wind farms online by feeding reactive power during system events. Until now it is common that wind turbines have a single response to these momentary voltage drops: they trip offline, protecting their functions until the grid recovers.

In order to the wind power plants to attend the fault ridethrough requirements besides providing the wind generator with appropriate technology it is necessary that the system protection be able to accomplish the task accordingly.

This paper aims to present the evaluation from the implementation of the LVRT curve in two numerical relays from different manufacturers. The features of the relays and the LVRT curve achieved are discussed. The functionality of the wind turbine grid protection system is tested in a simplified power system using the PSCAD/EMTDC simulation tool. The protection levels and the disconnection times of the wind power plant are defined according to the Brazilian grid code. Simulation results are presented and discussed.

The paper is organized in the following way: section 2 defines the low-voltage ride-through curve; section 3 presents the procedures to implement the LVRT in two relays of different brands; in section 4 simulation tests are performed in a simplified system with wind turbine taking into consideration the LVRT requirements in the system protection, and finally the conclusion are given in section 5 . 


\section{The LVRT Curve}

A voltage vs. time characteristic denoting the minimum required immunity of the wind power station at the point of common coupling (PCC) describes the low voltage ride-through capability. The demanded fault behavior of a wind power plant can be summarized into the requirements based on the LVRT curve depicted in Fig.1.

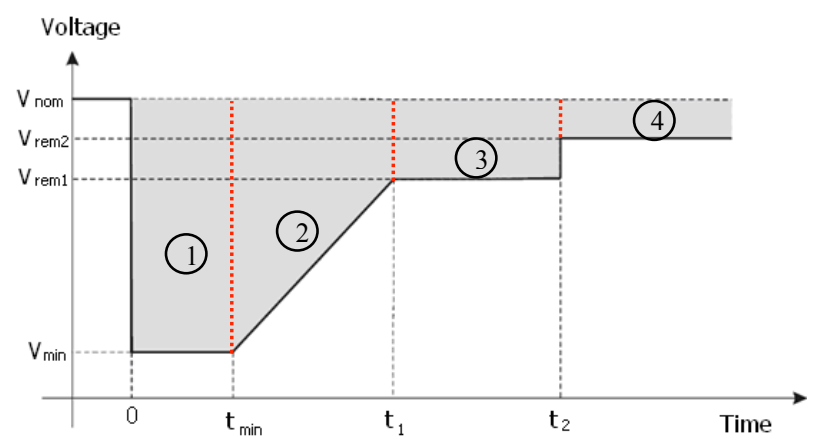

Fig. 1. Required ride-through voltage capability of wind power plants.

The curve can be divided into four areas according to the variation in voltage over time:

- For system faults that last up to $t_{\min }$ and the voltage magnitude at the PCC is equal to or greater than $\mathrm{V}_{\min }$ the wind power plant has to remain connected to the network. These boundaries define area 1 .

- Area 2 defines a linear growth recovery voltage from $V_{\min }$ to $V_{\text {rem1 }}$ in a period from $t_{\min }$ to $t_{1}$. The biggest challenge of adjusting of protection is to ensure the change of area 2 with the highest conformity possible during the restoration of voltage, because most relays only gives you the option of tweaking in discrete time intervals, and not with linear and continuous growth.

- Area 3 describes the system recovery, with voltage sag to $V_{\text {rem1 }}$ by $\left(t_{2}-t_{1}\right)$ seconds, and the area 4 the full normalization, where after $t_{2}$ seconds early voltage sag, the voltage is equal to or greater than $\mathrm{V}_{\text {rem2}}$, and protection should not operate.

When the voltage at the point of common coupling is above the LVRT curve (gray area) the wind farm must remain connected, and must be disconnected only if the voltage takes values below the curve.

During system faults and voltage sags a wind power plant has to supply maximum reactive current to the grid system without exceeding the transient rating of the plant.

The base values defined by the Brazilian system operator for the LVRT curve are listed in Table I [5].

Table I. - The LVRT by the Brazilian grid code.

\begin{tabular}{|l|c|c|c|}
\hline $\mathrm{V}_{\min }$ & $0.20 \mathrm{pu}$ & $\mathrm{t}_{\min }$ & $0.5 \mathrm{~s}$ \\
\hline $\mathrm{V}_{\text {rem1 }}$ & $0.85 \mathrm{pu}$ & $\mathrm{t}_{1}$ & $1.0 \mathrm{~s}$ \\
\hline $\mathrm{V}_{\mathrm{rem} 2}$ & $0.90 \mathrm{pu}$ & $\mathrm{t}_{2}$ & $5.0 \mathrm{~s}$ \\
\hline
\end{tabular}

\section{The Numerical Relays}

A protective numerical relay is a device with a collection of interacting specific purpose blocks as central processing unit, one or two microprocessors, memories, analog and digital I/O, A/D conversion, HMI, communication, real time clock, power source and software tool. The multiple block functions provide the necessary computational performance enabling them to perform multi-protection functions, metering, monitoring, fault recording, setting groups, oscillography and continuous self-monitoring [6].

The main difference between numerical and conventional relays (electromechanical and solid- state relays for instance) is that the former has their logic implemented in software and microprocessor technology.

The relay programmable logic allows the user to customize the functions of control and protection, in relay input and output variables and LED indications. The scheme consists of programmable logic gates and timers of general use. The LVRT curve can thus be defined using custom programming feature of numerical relays.

Two relays from different brands were investigated and tested in laboratory. The objective was to determine how to use the functions available to implement the LVRT curve.

\section{A. Numerical Protective Relay 1}

The numerical relay 1 is primarily used as equipment of protection and control of medium voltage lines. The relay software, with the function of interfacing with the equipment, either local or remotely, provides access and changing all the parameterizations and relay settings. Settings and simulations in relay 1 were made through its software that allows making adjustments to each function of protection, logical programs and simulate tests.

To better represent the curve LVRT shown in Fig. 1, specially the area 2, the function "Measures" in the protection menu was used, which from measurements such as voltage, allows you to create generic protections, according to the need of system protection.

The option Measures provides a total of eight generic measures, which via programmable logic can generate signal trip. Each generic measure can only be used by a phase-to-neutral or phase-to-phase quantity. In order to ensure better precision in the representation of the curve LVRT each generic measure of relay 1 was configured to one of the phase-to-neutral voltages. The curve has been divided into eight points or ranges. Table II shows the range of magnitude of voltage sag and time-delay that functions Measure and Timer must trip the circuit breaker.

Table II. - Discretization of the curve LVRT.

\begin{tabular}{|c|c|c|c|}
\hline $\begin{array}{c}\text { Voltage sags } \\
{[\mathrm{pu}]}\end{array}$ & $\begin{array}{c}\text { Time- } \\
\text { delay [s] }\end{array}$ & $\begin{array}{c}\text { Measure } \\
\text { Function }\end{array}$ & $\begin{array}{c}\text { Timer } \\
\text { Function }\end{array}$ \\
\hline $\mathrm{V}<0.20$ & Ins. & Measure 1 & - \\
\hline $0.20<\mathrm{V}<0.33$ & 0.5 & Measure 2 & Timer 3 \\
\hline $0.33<\mathrm{V}<0.46$ & 0.6 & Measure 3 & Timer 4 \\
\hline $0.46<\mathrm{V}<0.59$ & 0.7 & Measure 4 & Timer 5 \\
\hline $0.59<\mathrm{V}<0.72$ & 0.8 & Measure 5 & Timer 6 \\
\hline $0.72<\mathrm{V}<0.85$ & 0.9 & Measure 6 & Timer 7 \\
\hline
\end{tabular}




\begin{tabular}{|l|l|l|l|}
\hline $0.85<\mathrm{V}<0.90$ & 1.0 & Measure 7 & Timer 8 \\
\hline $\mathrm{V}<0.90$ & 5.0 & Measure 8 & Timer 9 \\
\hline
\end{tabular}

The Measure 1 was configured to send instantaneous opening signal to the circuit breaker when the voltage magnitude at the PCC is below $0.2 \mathrm{pu}$. Block Measure 2 activates its output when the voltage magnitude at the PCC reaches a value below the previously configured interval. With this, the input of the logical state of Timer 3 changes, starting counting of time. If after the given time the input of Timer 3 continues active a trip signal is sent to the circuit breaker. After carrying out configurations and logical programming, data were passed to relay 1 through the serial port.

The logic implemented was tested applying various voltage sags and observing whether the time for the opening of the circuit breaker was compatible. For voltage sag to $70 \%$ for example, the breaker opening command was sent after $0.492 \mathrm{~s}$, very close to the specified value of $0.500 \mathrm{~s}$. The error was $1.6 \%$, which makes the result acceptable. For all other tracks of voltage sag the results were satisfactory with minor errors.

Fig. 2 shows the achieved curve for the relay 1. During the voltage restoration time interval it appears that the curve is not smooth but instead discrete, which describes the limitation of the relay.

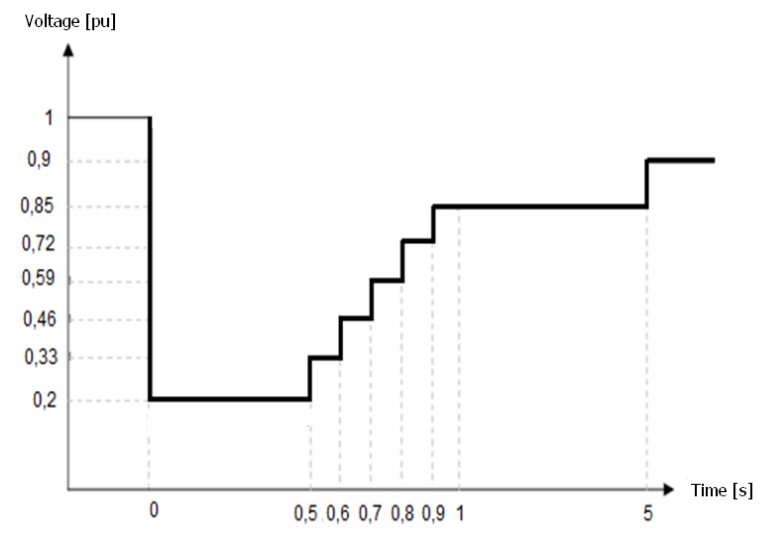

Fig. 2. Curve LVRT for numerical protective relay 1.

\section{B. Numerical Protective Relay 2}

Relay 2 is suited for transmission lines and feeders for protection, control and monitoring of overhead transmission lines and underground cables.

Relay 2 settings were made via software made available by the manufacturer, which allows making adjustments to each protection function, logical programmes, oscillography readout, among other functions.

As in the previous relay, this device displays only the settings option in discrete time intervals, which makes difficult the implementation of the LVRT curve during the ramp interval representing the restoration of voltage. This equipment has four groups of independent protection settings, but only one group setting remains active at a time. Changing group settings can be performed manually, or by external digital inputs. Each group in turn has two levels adjustment. To improve the accuracy of LVRT curve, we considered the change of group setting in real time, but this implies loss of settings for other functions of relay.

The control of group settings is accomplished through two opto-isolated inputs, which can be accessed through logical variables "DDB 526" and "DDB 527" in the relay software menu. The combination of the logical state of each of the two variables makes it possible to change to another group of settings. The combinations are shown in Table III.

Table III. - Change of group settings via logical variables in relay 2 .

\begin{tabular}{|c|c|c|}
\hline \multicolumn{2}{|c|}{ Logical Variable State } & \multirow{2}{*}{$\begin{array}{c}\text { Group Setting } \\
\text { Selected }\end{array}$} \\
\cline { 1 - 2 } DDB 526 & DDB 527 & Group 1 \\
\hline 0 & 0 & Group 2 \\
\hline 0 & 1 & Group 3 \\
\hline 1 & 0 & Group 4 \\
\hline 1 & 1 & \\
\hline
\end{tabular}

Each group setting allows two configurations per protection function, which can be instantaneous or timed. Each of the configurations has two input logical variables associated with. For the function of voltage sags, variables are: "V $<1$ Start", "V $<2$ Start", "V $<1$ Trip" and "V $<2$ Trip". The first two relate to the beginning of the event log, and the two latest sending signal tripping after time settings. The numbers "1" and " 2 " of variables relate to which of the two configurations available the variable belongs to. The four variables are the same for any group setting, sending the signal for the selected group setting. For programmable logic was set that the variable "V $<1$ Start" would be the indicator of voltage sags (voltage less than $90 \%$ of nominal voltage), triggering the Timers and changes of group settings. The variable "V $<2$ Start" has different bounds according to the group setting, the voltage magnitude and the time setting, drawing the LVRT curve and sending the signal tripping when the voltage is less than the established value. Settings of the variables are listed in Table IV.

Table IV. - Setting the undervoltage protection function.

\begin{tabular}{|c|c|c|c|c|c|}
\hline \multicolumn{2}{|c|}{ Group Settings } & \multicolumn{2}{|c|}{ Setting "V $<1$ " } & \multicolumn{2}{c|}{ Setting "V $<2$ " } \\
\hline Group's & Timer & $\begin{array}{c}\text { Value } \\
{[\mathrm{pu}]}\end{array}$ & $\begin{array}{c}\text { Trip } \\
{[\mathrm{s}]}\end{array}$ & $\begin{array}{c}\text { Value } \\
{[\mathrm{pu}]}\end{array}$ & $\begin{array}{c}\text { Trip } \\
{[\mathrm{s}]}\end{array}$ \\
\hline 1 & 0.00 & 0.9 & 0 & 0.20 & Ins. \\
\hline 2 & 0.50 & 0.9 & 0 & 0.44 & Ins. \\
\hline 3 & 0.66 & 0.9 & 0 & 0.66 & Ins. \\
\hline 4 & 0.85 & 0.9 & 0 & 0.85 & Ins. \\
\hline
\end{tabular}

Table IV contains information about the time delay for change of group setting and the values for each setting group configuration.

When testing the logic programmed, group settings changes have not occurred. After contacting the manufacturer's representatives, we were informed that the relay model used in this investigation is not possible to change the group settings by internal logic. The operation of the relay was limited only to settings of group 1. Thus, the curve obtained from the implementation in the numerical protective relay 2 is presented in Fig. 3. 


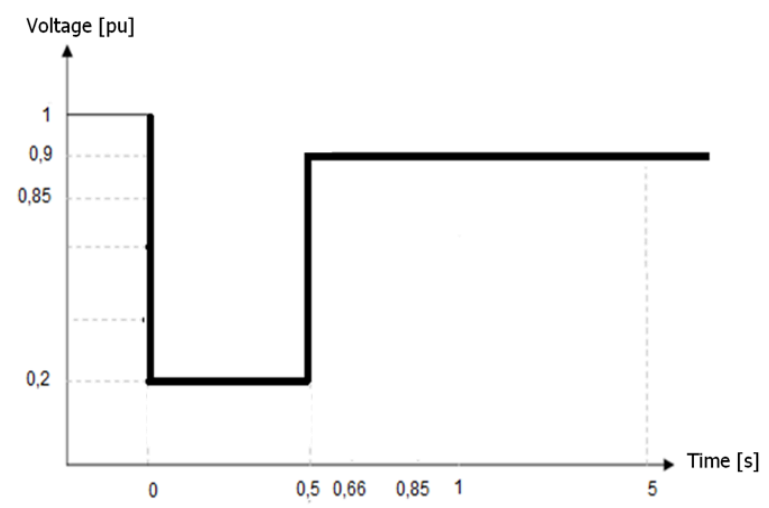

Fig. 3. Curve LVRT for numerical protective relay 2.

\section{Test System}

The one-phase diagram of the test system used for simulation of the protection system operation under grid fault using the PSCAD/EMTDC simulation tool is illustrated in Fig. 4. The wind farm use doubly fed induction generators (DFIG), currently the most used generator type [7]. The circuit used is available at [8].

\section{A. DFIG Machine}

Variable speed wind turbines use power converters to perform both active and reactive power control and also to maximize the energy captured as well as to reduce the mechanical stress and noise. In the case of DFIG wind turbines, the direct connection of the generator stator to the grid results in severe transients in case of large grid disturbances. The stator contributes a high initial short circuit current while large currents and voltages are also induced in the rotor windings as a consequence of the fundamental flux linkage dynamics of the generator.

Furthermore, the voltage sag at the wind turbine terminals reduces accordingly the power output of the grid side rotor converter leading to an increase of the dc bus capacitor voltage. To protect the power converters from over voltages and over currents DFIGs must provide devices and extra control strategy as soon as such situations are detected [1].

For the simulation tests, the LVRT curve as given by the Brazilian grid code [5] has been represented in the protection device of the wind power plant connection bus. During and after grid fault, the voltage at the point of common coupling was compared with the LVRT reference curve and evaluated the performance of the protection system. For voltages values under the reference curve a trip signal was sent to open the circuit breaker disconnecting the wind power plant from the grid.

\section{B. Results Evaluation}

Three short circuit conditions were evaluated: a threephase fault because they are the most severe outage for power systems and two single-phase faults for being the most common in electrical systems [9].

According to the system operators' rules, the circuit breaker must open if the voltage on one or more phases reaches levels below the curve LVRT and close when all three phases reach values above the reference curve [5]. The crowbar protection of the wind turbine generator is on during the fault simulation in order to protect the machine and converters [1]. All faults are applied at the transformer high voltage bus.

\section{1) Three-phase short-circuit}

A three-phase-to-groud fault of 0.15 second was applied at the PCC. The short-circuit resistance considered was equal to 0.035 ohms.

Fig. 5 shows the curves LVRT (blue) and the rms voltage (red) at the PCC, whereas Fig. 6 shows the status of the circuit breaker BRK during the fault. The rms voltage was measured using 256 samples per cycle and $60 \mathrm{~Hz}$. It can be observed that when the rms voltage is under the LVRT curve the BRK is equal to 1 that means circuit breaker open.

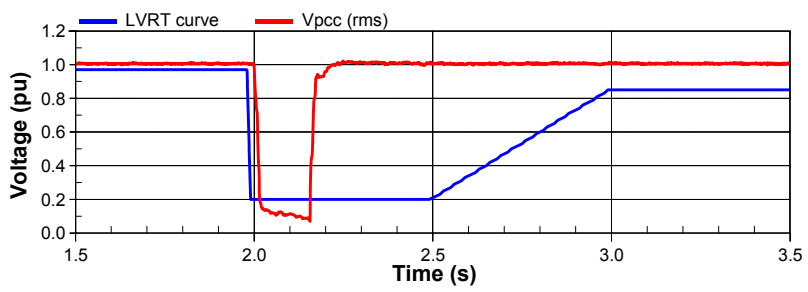

Fig. 5. Curves LVRT and rms voltage during a three-phase fault.

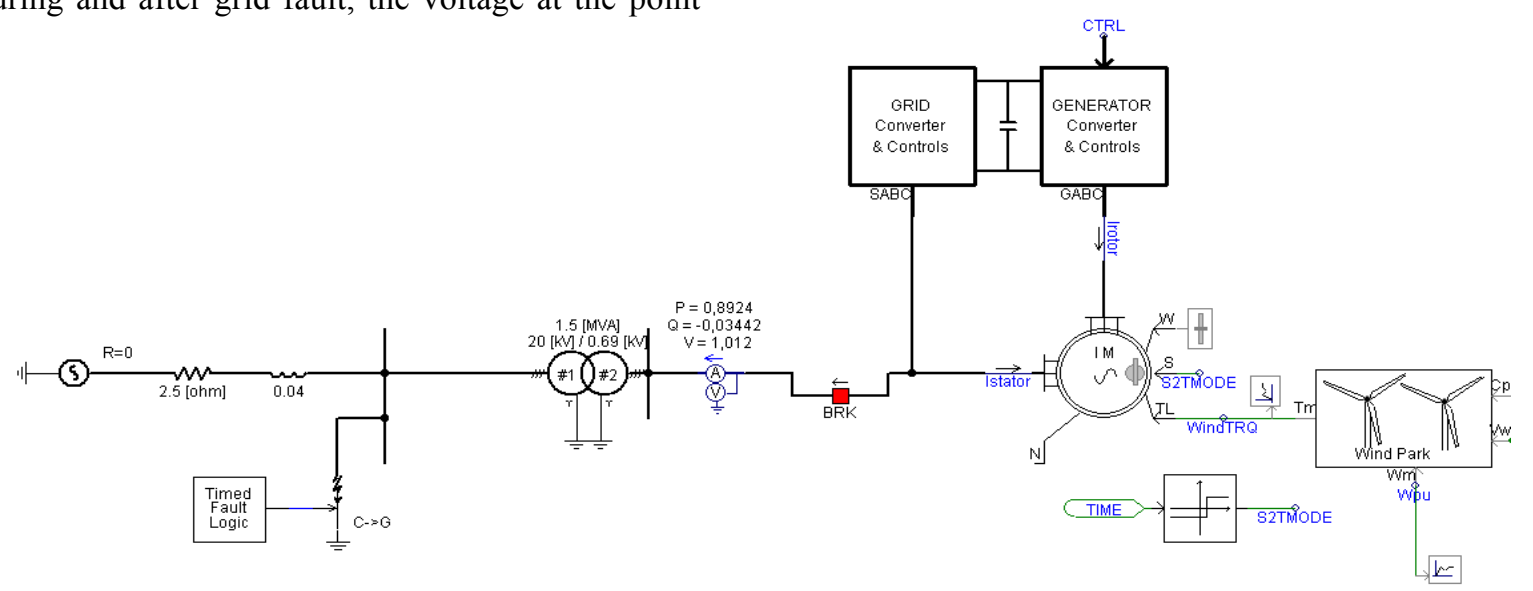

Fig. 4. System used for fault simulation. (Source: [8]) 


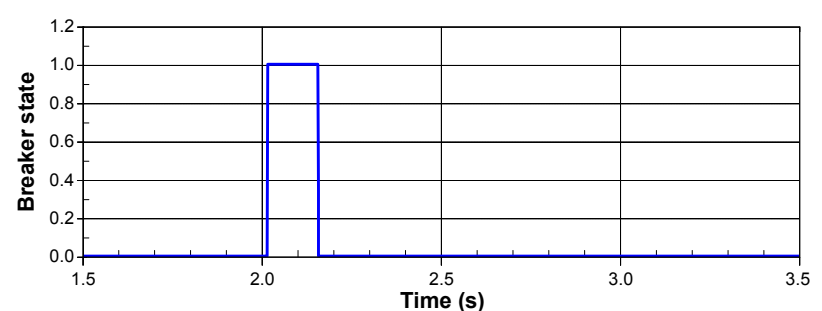

Fig. 6. The circuit breaker state is ON (1) during violation of the LVRT requirements and OFF (0) after voltage restoration.

Fig. 7 shows the current in the rotor of the wind turbine generator. It can be observed an oscillatory transition current during the short circuit and, soon after the closing of the circuit breaker.

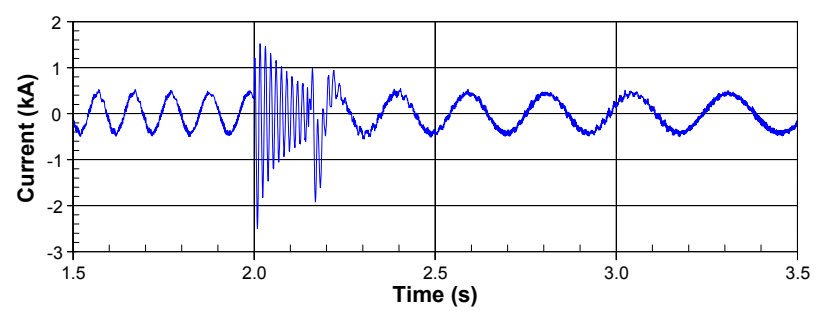

Fig. 7. Current waveform in phase $\mathrm{A}$ in rotor-generator during the short circuit.

\section{2) Single-phase short-circuit 1}

A single-phase fault in phase $\mathrm{A}$ of $0.5 \mathrm{~s}$ and fault resistance equal to $3 \mathrm{ohms}$ is evaluated. Fig. 8 shows the voltages in phases $\mathrm{A}, \mathrm{B}$ and $\mathrm{C}$ for the short circuit at the point of common coupling.

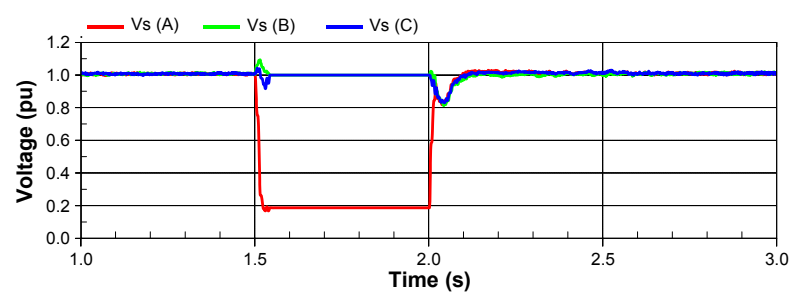

Fig. 8. RMS phase-to-neutral voltage curves at the PCC.

Fig. 9 shows the current waveforms in the rotor of the generator. During the fault the current in the rotor is smaller than the pre-fault current.

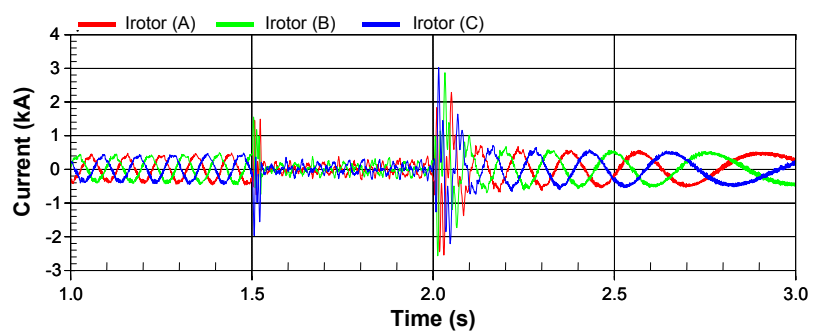

Fig. 9. Current in the rotor of the generator

The Brazilian grid code defines that if there are voltage sags in one or more phases in the point of common coupling of a wind generation plant, the wind turbines must continue to operate if the voltage at its terminals remain above the LVRT curve as defined in Tab. I. Based on this directive the rms voltage at the point of common coupling can be measured using two different approaches. The first one considers the voltage at the fault phase. In these circumstances the voltage sag in phase $\mathrm{A}$ is smaller than that in the LVRT curve and a tripping signal is sent to the circuit breaker as shown in Figs. 10 and 11 (red curve). Due to the severity of the voltage sag, the circuit breaker was open and the generator could not contribute to the restoration of voltage at PCC.

The second approach measures the rms voltage at the PCC as given in (1). In this condition the aggregated voltage is above the LVRT curve and the wind turbine is not disconnected from the grid.

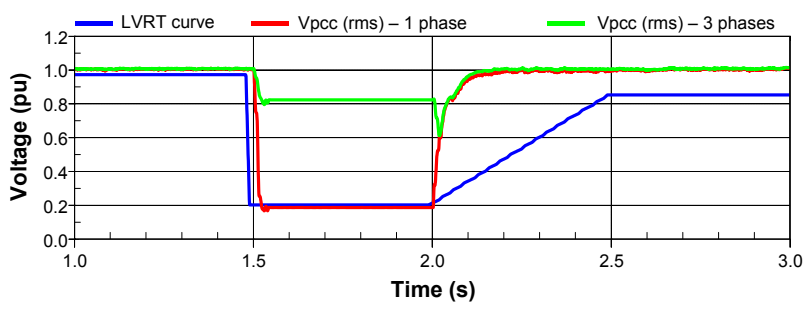

Fig. 10. Curve LVRT and rms voltage at the PCC.

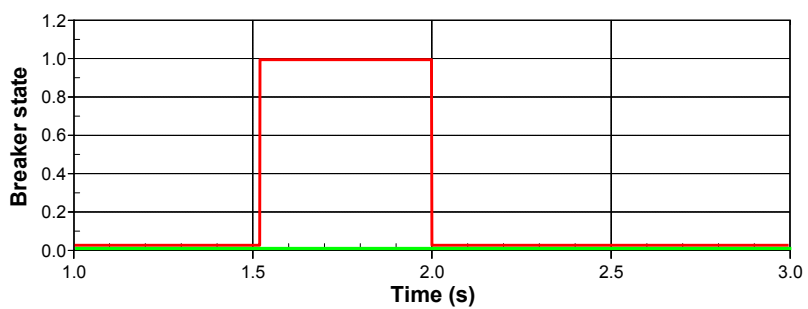

Fig. 11. The circuit breaker state is ON (1) when the faulted phase is measured and OFF ( 0$)$ when the aggregated voltage is measured.

$$
V_{P C C_{3 \phi}}=\sqrt{\frac{1}{3}\left(V_{A_{r m s}}^{2}+V_{B_{r m s}}^{2}+V_{C_{r m s}}^{2}\right)}
$$

\section{3) Single-phase short-circuit 2}

A single-phase short-circuit was applied in phase A with duration of $0.65 \mathrm{~s}$ and resistance of $10 \mathrm{ohms}$. The rms voltages in phases $\mathrm{A}, \mathrm{B}$ and $\mathrm{C}$ for a short circuit in phase A are plotted in Fig. 12. The fault was longer and less severe than the previous ones. It can also be observed that the voltage in phase $\mathrm{C}$ has dropped during the fault.

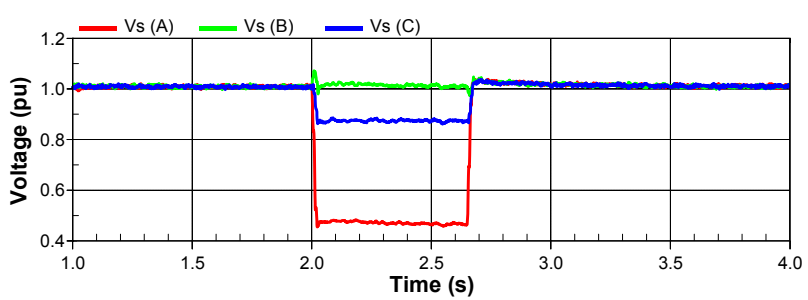

Fig. 12. Voltage curves at the terminals of the machine during the short circuit.

Figs. 13 and 14 show respectively the state of the circuit breaker BKT and curves LVRT and rms voltage of phase $\mathrm{A}$ at the PCC. 


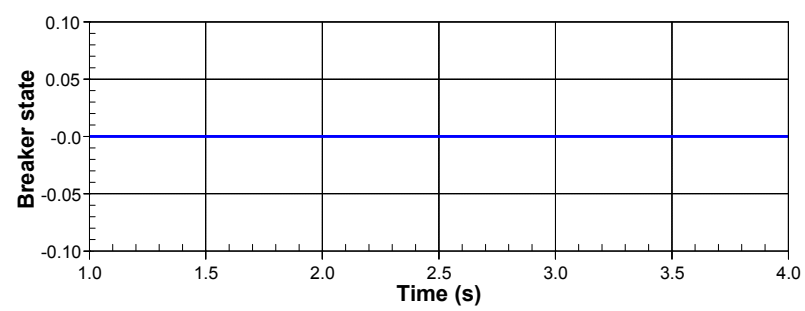

Fig. 13. State of the circuit breaker during short-circuit and after the restoration of voltage.

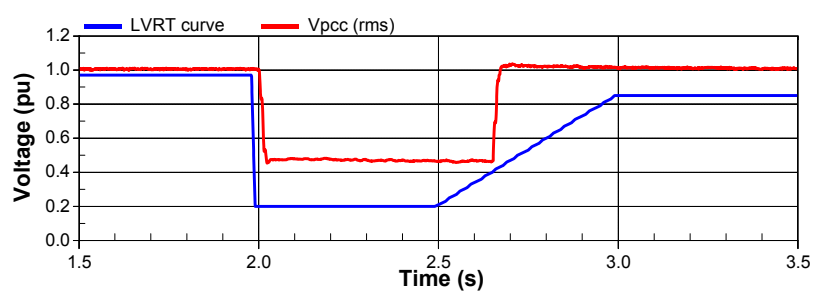

Fig. 14. Curve LVRT and rms voltage during fault.

Fig. 15 shows the currents in the machine rotor. In this case, the currents have entered into steady state, and the magnitude of the current reaches two times their nominal value.

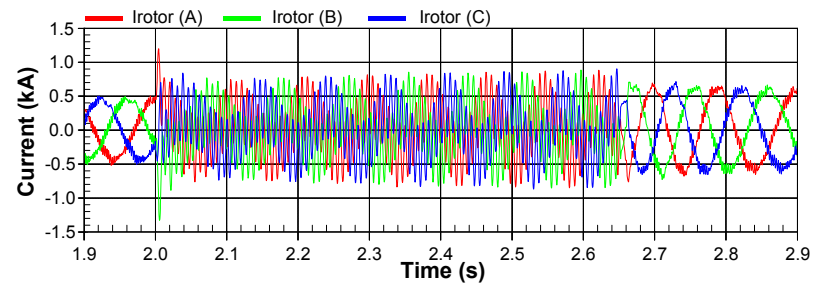

Fig. 15. Current waveforms in the rotor generator

Fig. 16 shows the contribution of active power and reactive power from the wind turbine generator during the fault. The reactive power contributes to the bus voltage restoration.

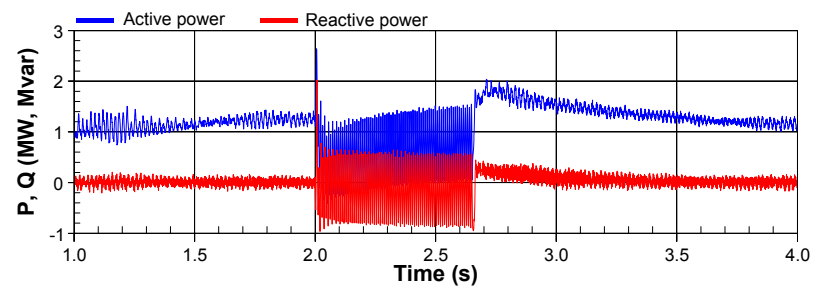

Fig.16. Active and reactive power supplied by the generator during the short circuit.

\section{Conclusion}

Numerical relays used in wind power plant substations in their great majority do not have specific logic to implement LVRT curves as required by the system operators.

The application of the low voltage ride-through curve, as given by the Brazilian grid code, in numerical relays from two different manufacturers has achieved satisfactory results for the relay from manufacturer 1, with the relay curve approximating the reference curve. For the other numerical relay from manufacturer 2 , the curve obtained is rectangular and the voltage condition required during the system restoration does not resemble the reference curve.

During the simulation of faults in the test system, it has been observed the production of reactive power during the fault to restore the system without the need of disconnecting the wind power plant, if the curve supportability should be applied.

The paper offer lessons learned and suggestions for future development of this custom programming feature of numerical relays.

\section{References}

[1] F.K.A. Lima, A. Luna, P. Rodriguez, E.H. Watanabe and F. Blaabjerg, "Rotor Voltage Dynamics in the DoublyFed Induction Generator during Grid Faults", IEEE Transactions on Power Electronics, vol. 25, $\mathrm{n}^{\circ} .1$, pp. 118130, 2010 .

[2] H. Leite, Ramalho, P., Silva, B., Fitero, R. Distributed Generation Protection Scheme to Permit "Ride-Through Fault". $20^{\text {th }}$ International Conference and Exhibition on Electricity Distribution. Prague, June/2009.

[3] Leao, R.P.S., Degner, T. and Antunes, F.L.M. "An Overview on the Integration of Large-Scale Wind Power into the Electric Power System." ICREPQ 2007.

[4] C. Rahmann, H.J. Haubrich, L. Vargas, M.B.C. Salles "Investigation of DFIG with Fault Ride-Through Capability in Weak Power System." International Conference on Power Systems Transients (IPST2009) in Kyoto, Japan June 3-6, 2009.

[5] Operador Nacional do Sistema Elétrico - ONS. "Procedimentos de Rede". Setembro de 2005.

[6] L. Hewitson, M. Brown, and R. Balakrishnan. Power Systems Protection. 2004. Elsevier. ISBN 0750663979.

[7] A. D. Hansen and L. H. Hansen, "Market Penetration of wind turbine concepts over the years". Risø National Laboratory - Wind Energy Department, Denmark.

[8] PSCAD/EMTDC. [Online]. Available: www.pscad.com.

[9] B. de Mstz-Noblat, F. Dumas, C.Poulain. Caulculation os Short-Circuit Currents. Coletion Technique, Schneider Electric. $\mathrm{N}^{\circ} 158$, September 2005. 